\title{
Amelia: A Case Report and Literature Review
}

\author{
Fatemeh Eghbalian, ${ }^{1, *}$ Amine Sharif, ${ }^{1}$ and Amir Reza Monsef ${ }^{1}$ \\ ${ }^{1}$ Hamadan University of Medical Sciences, Hamadan, IR Iran \\ ${ }^{*}$ Corresponding author: Fatemeh Eghbalian, Hamadan University of Medical Sciences, Hamadan, IR Iran. Tel: +98-9181190121, Fax: +98-8112517910, E-mail: eghbalian_fa@yahoo.com
}

Received 2015 September 26; Accepted 2015 October 6

Keywords: Amelia, Micromelia, Malformations, Limbs, Infant, Newborn

\section{Dear Editor,}

Amelia, defined as the complete absence of the skeletal parts of a limb that occurs when the limb formation process is either prevented or interrupted very early in the developing embryo between 24 and 36 days following fertilization (1-4). Amelia is generally thought to be a sporadic anomaly. But more than $50 \%$ of the cases it is associated with major malformations in other organ systems (4). The malformations most frequently seen with Amelia include cleft lip and/or palate, body wall defect, malformed head, and defects of the neural tube, kidneys, and diaphragm (5-7). Facial clefts may be accompanied by other facial anomalies such as abnormally small jaw, and missing ears or nose. The body wall defects allow internal organs to protrude through the abdomen $(8,9)$. Head malformations may be minor to severe with a near absence of the brain. The diaphragm may be herniated or absent and one or both kidneys may be small or absent $(8,10)$.

Other abnormalities associated with Amelia include severe defects of the lungs, vertebrae, heart, internal and external genital system, and anus (10-13). There is usually severe growth deficiency, both before and after birth, and mental retardation may be present in survivors (10). Teratogens such as thalidomide and alcohol, vascular compromise by amniotic bands or other causes, and maternal diabetes have been reported to cause this severe limb deficiency (8-10).

The patient was a full-term male neonate, the first child of a 22 year old father and 26 year old mother. There was no consanguinity or any other relevant family history. There was no known teratogenic exposure or any problem during pregnancy. The height, weight, and head circumference were normal. The right arm was completely missing with a cherry sized skin bulging on the lateral end of the right clavicle (Figure 1). In physical examination an imperforate anus was also visible (Figure 2).
The ultrasonography showed only one kidney, right kidney was absent, but in VCUG left kidney had reflux grade 5 and right kidney reflux grade 4 (Figure 3 ). Regarding rising BUN and Cr levels, DMSA was done that showed poor function of the left kidney and the function of the right kidney was moderately to severely decreased.

Echocardiography revealed an ASD. X-ray of vertebrae showed hemivertebra of L5 (Figure 4). No other anomalies were found.

Prior to clinical observation of absent limbs, certain signs in the pregnant mother may indicate a greater likelihood of amelia. Abnormal vaginal bleeding, diabetes mellitus, and toxemia can all be associated with amelia of the fetus $(4,9)$. An increased alfa fetoprotein in the maternal blood may indicate neural tube defects that can accompany limb defects (12).

Besides seeing missing limbs by ultrasound, signs in the fetus accompanying amelia include breech and other non-cephalic presentations at birth, a single artery in the umbilical cord, low placental weight and extremely low birth weight, not accounted for by the lack of limbs (13).

This report presents a case of amelia with imperforate anus, hemivertebra in L5, ASD and renal involvement.

VACTERL associated is a disorder that affects many body systems. VACTERL stands for vertebral defects, anal atresia, cardiac defects, trachea-esophageal fistula, renal anomalies, and limb abnormalities. Cases with VACTERL association typically have at least 3 of these characteristic features (14). Limb abnormalities are seen in 40 - 50\% of VACTERL association. These abnormalities most commonly include poorly developed or missing thumbs or underdeveloped forearms and hands but amelia is a rare form of limb abnormality in VACTERL $(4,14,15)$.

Prenatal diagnosis including detailed ultrasound and amniocentesis examination play a major role in counseling parents with fetal anomalies including amelia.

Copyright (C) 2015, Growth \& Development Research Center. This is an open-access article distributed under the terms of the Creative Commons Attribution-NonCommercial 4.0 International License (http://creativecommons.org/licenses/by-nc/4.0/) which permits copy and redistribute the material just in noncommercial usages, provided the original work is properly cited. 
Eghbalian F et al.

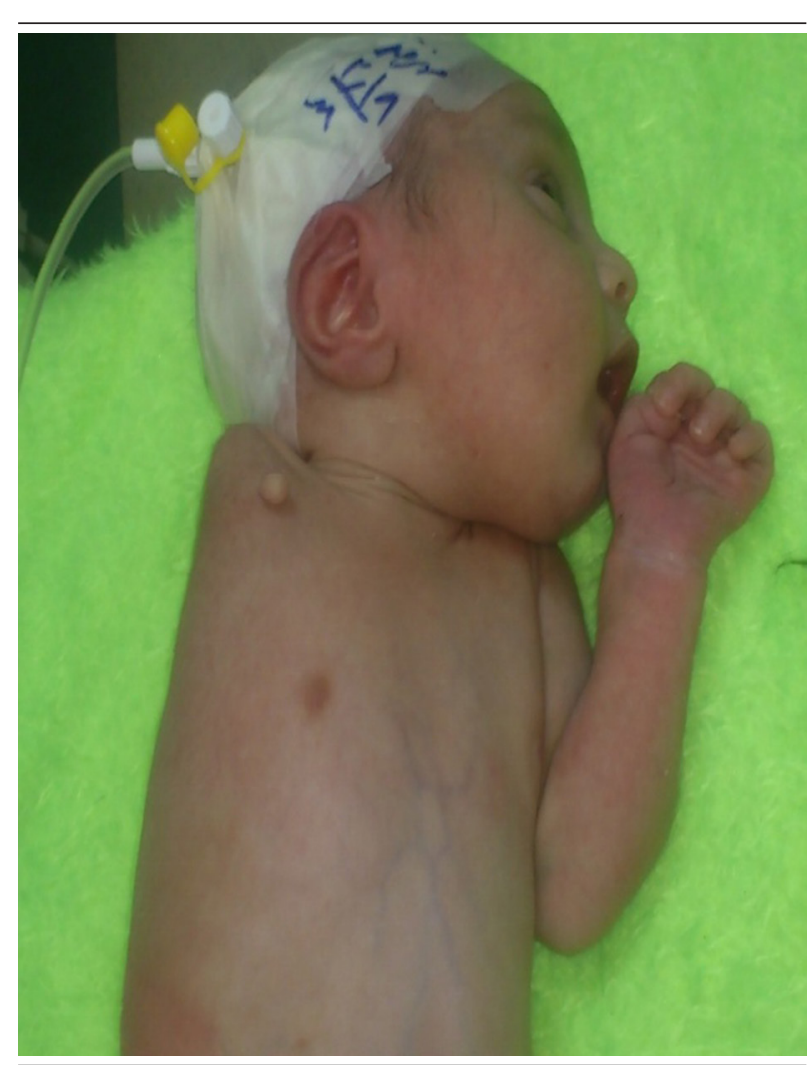

Figure 1. Neonate With Amelia

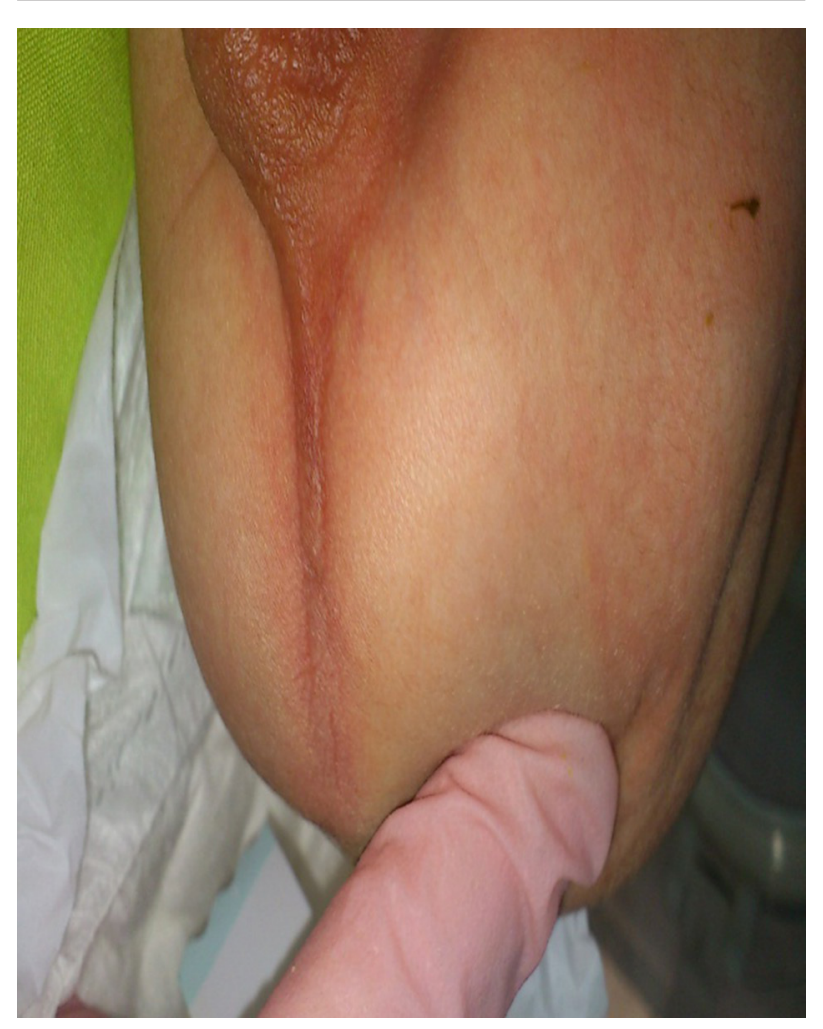

Figure 2. Imperforate Anus in Neonate With Amelia

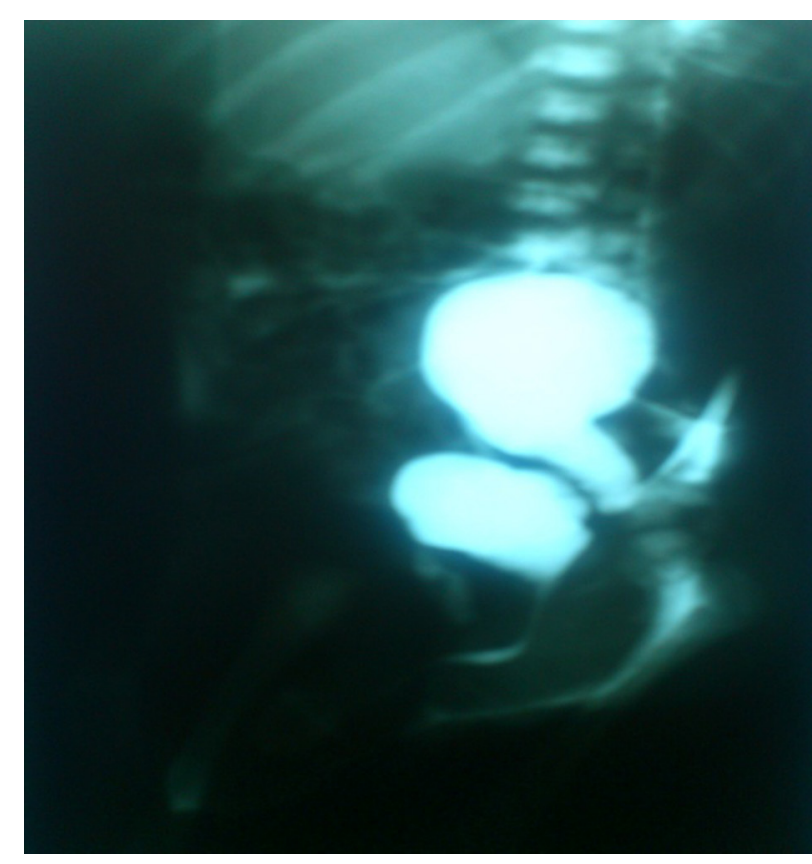

Figure 3. VCUG: Reflux Grade 5 in the Left and Grade 4 in the Right Kidney

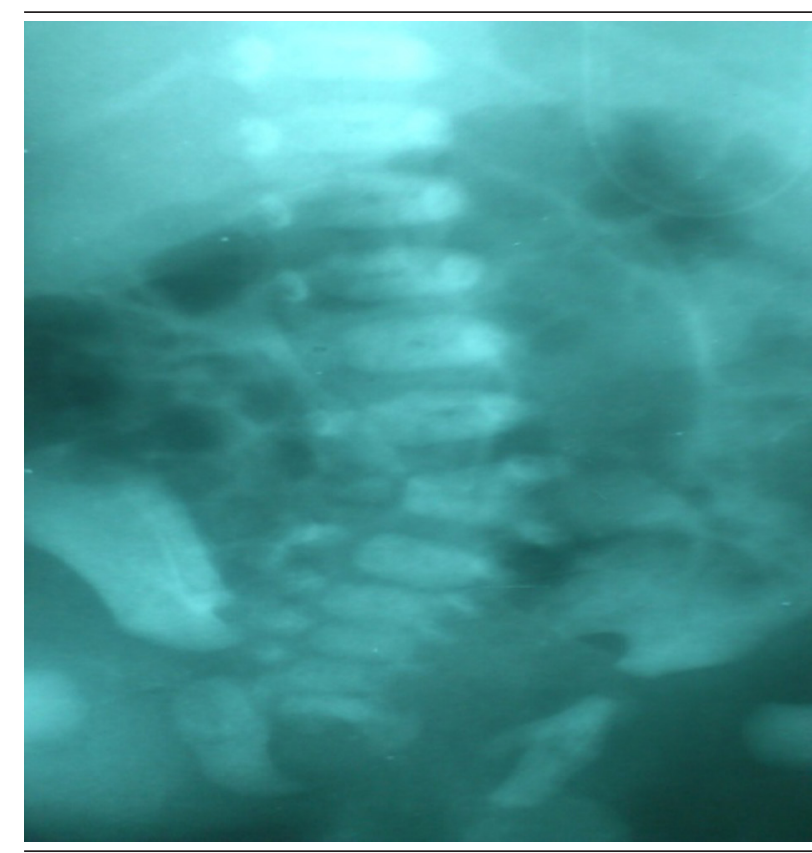

Figure 4. Hemivertebra in L5

\section{References}

1. Gupta P, Kumar A. Amelia-meromelia sequence with atrial septal defect-a rare occurrence. Fetal Pediatr Pathol. 2014;33(2):92-7. doi: 10.3109/15513815.2013.864348. [PubMed: 24328941]

2. Klaassen Z, Choi M, Musselman R, Eapen D, Tubbs RS, Loukas M. A review of supernumerary and absent limbs and digits of the upper limb. Surg Radiol Anat. 2012;34(2):101-6. doi: 10.1007/s00276011-0871-1. [PubMed: 22068244] 


\section{Eghbalian F et al.}

3. Bianca S, Bartoloni G, Libertini C, Boemi G, Barrano B, Cataliotti A, et al. Fetal upper limb amelia with increased nuchal translucency. Congenit Anom (Kyoto). 2009;49(3):121-2. doi: 10.1111/j.17414520.2009.00238.x. [PubMed: 20002906]

4. Lenz W. Genetics and limb deficiencies. Clin Orthop Relat Res. 1980;(148):9-17. [PubMed: 7379414]

5. Froster-Iskenius UG, Baird PA. Amelia: incidence and associated defects in a large population. Teratology. 1990;41(1):23-31. doi: 10.1002/tera.1420410104. [PubMed: 2305372]

6. Evans JA, Vitez M, Czeizel A. Patterns of acrorenal malformation associations. Am J Med Genet. 1992;44(4):413-9. doi: 10.1002/ ajmg.1320440405. [PubMed:1442878]

7. Mastroiacovo P, Kallen B, Knudsen LB, Lancaster PA, Castilla EE, Mutchinick $\mathrm{O}$, et al. Absence of limbs and gross body wall defects: an epidemiological study of related rare malformation conditions. Teratology.1992;46(5):455-64. doi:10.1002/tera.1420460510. [PubMed:1462250]

8. Smithells RW, Newman CG. Recognition of thalidomide defects.J Med Genet. 1992;29(10):716-23. [PubMed:1433232]

9. Bermejo-Sanchez E, Cuevas L, Amar E, Bakker MK, Bianca S, Bianchi F, et al. Amelia: a multi-center descriptive epidemiologic study in a large dataset from the International Clearinghouse for Birth Defects Surveillance and Research, and overview of the literature. Am J Med Genet C Semin Med Genet. 2011;157C(4):288-304. doi:10.1002/ajmg.c.30319. [PubMed: 22002956]

10. Sousa SB, Pina R, Ramos L, Pereira N, Krahn M, Borozdin W, et al. Tetra-amelia and lung hypo/aplasia syndrome: new case report and review. Am J Med Genet A. 2008;146A(21):2799-803. doi: 10.1002/ajmg.a.32489. [PubMed: 18837045$]$

11. Krahn M, Julia S, Sigaudy S, Liprandi A, Bernard R, Gonnet K, et al. Tetra-amelia and lung aplasia syndrome: report of a new family and exclusion of candidate genes. Clin Genet. 2005;68(6):558-60. doi:10.1111/j.1399-0004.2005.00531.x. [PubMed:16283889]

12. Kallen B, Rahmani TM, Winberg J. Infants with congenital limb reduction registered in the Swedish Register of Congenital Malformations. Teratology. 1984;29(1):73-85. doi: 10.1002/ tera.1420290109. [PubMed: 6701808]

13. Song SY, Chi JG. Tri-amelia and phocomelia with multiple malformations resembling Roberts syndrome in a fetus: is it a variant or a new syndrome? Clin Genet. 1996;50(6):502-4. [PubMed: 9147883]

14. Eghbalian F, Monsef A, Mousavi-Bahar SH. Urinary tract and other associated anomalies in newborns with esophageal atresia. Urol J. 2009;6(2):123-6. [PubMed:19472132]

15. Goh ES, Li C, Horsburgh S, Kasai Y, Kolomietz E, Morel CF. The Roberts syndrome/SC phocomelia spectrum--a case report of an adult with review of the literature. Am J Med Genet A. 2010;152A(2):4728. doi:10.1002/ajmg.a.33261. [PubMed: 20101700] 